\title{
Efficacy of active cooling for controlling residual stresses in friction stir welds
}

\author{
D. G. Richards ${ }^{1}$, P. B. Prangnell*1 ${ }^{*}$ P. J. Withers ${ }^{1}$, S. W. Williams ${ }^{2}$, T. Nagy ${ }^{2}$ and \\ S. Morgan ${ }^{3}$
}

This paper investigates the effect of active cooling on the development of welding stresses during friction stir welding by finite element modelling. The primary aim was to see if cooling powers, corresponding to those currently obtainable using liquid $\mathrm{CO}_{2}$ cooling systems applied in practically feasible locations could bring about a significant reduction in weld residual stress. Various cooling strategies were examined. The simulations revealed that a large reduction in residual stress can be obtained, particularly at the weld line, depending on the size, power and positioning of the cooling sinks. A heat sink placed as close as possible behind the heat source had the greatest effect on reducing the build up of tensile stresses. All the approaches tended to reduce the weld centreline stress more effectively than those at the heat affected zone/ thermomechanically affected zone boundary (i.e. below the edge of the tool shoulder).

Keywords: Thermal tensioning, Residual stress, Friction stir welds, Low distortion, Thermal tensioning, Aluminium

\section{Introduction}

Friction stir welding (FSW) is an attractive process for joining aluminium alloys. It avoids many of the issues associated with fusion welding, such as poor weld metal properties, porosity and hot cracking. The FSW process, as applied to aluminium alloys, has been described in detail elsewhere. ${ }^{1}$ In outline, it involves a rotating tool consisting of a cylindrical shoulder and pin. The tool is plunged into the weld line until the shoulder contacts. Once the material is sufficiently hot, from frictional heating and plastic work, the tool traverses along the weld line and the hot plasticised material is extruded via the rotating pin, while constrained laterally by the surrounding colder metal and vertically between the shoulder and backing bar, to fill in behind the probe and form a joint. Although a solid state welding method, the welds can still suffer from significant levels of residual stress, and associated distortion, which can be similar in magnitude to that found in fusion welds. ${ }^{1-4}$

It is well known that tensile residual stresses in welded structures can have a negative impact on service life, ${ }^{5}$ particularly on fatigue and stress corrosion performance. ${ }^{5-8}$ It is thus desirable to reduce their level as far as possible. A number of techniques have been proposed for controlling stresses in welding, including both mechanical (e.g. Refs. 3 and 7-10) and thermal tensioning methods (e.g. Refs. 11-16). Previously, the

${ }^{1}$ School of Materials, Manchester University, Grosvenor St. Manchester M1 7HS, UK

${ }^{2}$ Cranfield University, Welding Engineering Research Centre, Bedfordshire MK43 OAL, UK

${ }^{3} \mathrm{BAE}$ Systems, Optics and Laser Technology Department, Advanced Technology Centre, PO box 5, FPC 267, Bristol BS12 7QW, UK

*Corresponding author, email philip.prangnell@manchester.ac.uk authors have investigated the potential of global mechanical tensioning for residual stress control in FSW. ${ }^{17}$ It was found to be extremely effective and, with sufficient applied force, could even be used to generate compressive residual stresses along the weld line. However, this technique suffers from some important practical limitations, in that very large loads are required and it can only be applied to linear welds and a limited range of component configurations. The application of forces locally using rollers appears to be a promising alternative option and recent evidence suggests that it is best applied directly to the weld line after welding has been completed. ${ }^{10}$

Thermal tensioning involves either heating or cooling the plates during welding. The resulting local thermal stresses either prevent the formation of, or subsequently reverse, the misfits that welding would otherwise introduce into the plate. Although this can be achieved by heating, for thermally sensitive materials like high strength Al alloys, it is more sensible to use cooling. Various types of cooling medium can be used, including water ${ }^{18}$ liquid nitrogen, and semisolid (snow) or liquid $\mathrm{CO}_{2}{ }^{16}$ This can be applied globally ${ }^{11}$ or locally, with the sources/sinks moving with the welding head. Local thermal tensioning has been referred to previously as dynamically controlled low stress, no distortion welding (DC-LSND) $)^{12-16,18}$ and was first developed by Guan et $a l .{ }^{13}$ for application to arc welding steel. Compared with mechanical tensioning, DC-LSND is more flexible and easier to apply industrially. It is also worth noting that DC-LSND methods are better suited to FSW than fusion welding, as there is no arc and/or shielding/ plasma gasses involved. Nevertheless, in previous work on arc welding ${ }^{13}$ and laser welding ${ }^{14,15}$ of low conductivity stainless steels notable improvements have 
been found using this approach. Van der Aa et al. ${ }^{15}$ has shown that when the cooling sink is placed behind the heat source it should be as intense, as small, and as close to the weld pool as possible, in order to obtain the greatest improvement.

At present the potential benefits for highly thermally conducting aluminium alloys have been relatively unexplored. Luan et al. ${ }^{18}$ recently demonstrated a $60 \%$ reduction in the peak residual stresses by the application of a water spray behind the tool in FSW, while preliminary experiments by Williams et al. ${ }^{9,16}$ on an AA 2024-T3 friction stir weld produced promising results. They found that the application of liquid $\mathrm{CO}_{2}$ cooling behind the tool can give a significant reduction in residual stress at the weld line, with the peak stresses at the edge of the heat affected zone (HAZ) being more modestly reduced. Apart from these experimental trials, no systematic study has been undertaken nor modelling used to optimise the tensioning arrangement, although some numerical work has been applied to thermal tensioning for various fusion welding configurations. ${ }^{14,15,19}$

Previously, the authors have validated a finite element (FE) model to predict stress development in friction stir welds in order to see how global mechanical tensioning could be used to control residual stress. ${ }^{17,20}$ These predictions were compared to synchrotron X-ray and neutron diffraction data showing good agreement. ${ }^{21}$ Here the authors have adapted the model to examine the effect of local thermal tensioning on residual stress. A key aim has been to examine the extent to the tensioning can be manipulated within practical limits, in order to 'intelligently' optimise the process and thereby explore its potential for residual stress mitigation in FSW.

\section{Methodology}

Various steps are taken in this paper to examine the efficacy of thermal tensioning as applied to aluminium FSW. First, the cooling capability of moving and stationary systems has been quantified through a series of calibration experiments. These cooling capabilities have then been incorporated into an FSW weld model that has already been validated against experiment and which includes the softening of AA 2024 as a function of thermal excursion. The model has then been compared against the available thermal tensioning experiments in the literature. The model is then used to investigate the efficacy of various cooling strategies and to identify practically achievable conditions that will lead to significant stress control.

\section{Finite element modelling}

The FE model, has been described in detail elsewhere. ${ }^{17,20}$ It comprises two sequentially coupled threedimensional simulations. First, a calibrated heat transfer model is used to reproduce the thermal field. This is then input into a stress analysis model along with the imposed boundary constraints. In the model the welding process is represented solely in terms of a heat source, with the metal flow and mechanical effects of the tool neglected. As a result, the findings have relevance to a wide range of welding processes. This approach was adopted, in part, because previous work has shown that the thermal profile is the predominant cause of residual stress, ${ }^{2,17}$ and second because it is computationally impractical to develop a fully coupled thermoplastic model for the extensive material flow that occurs in FSW.

Capturing material softening/hardening as the alloy undergoes a thermal excursion is key for the accurate modelling of the welding of age hardening alloys. ${ }^{22}$ The model used here for AA 2024 was described and validated in Ref. 17. In essence, it simulates the effect of material softening due to heating and microstructural changes that occur during the welding thermal cycle, caused by heating and aging in the thermomechanically affected zone (TMAZ) and HAZ.

\section{Heat source representation}

In the model the heating effect of the tool is represented by a circular surface source for the shoulder and a cylindrical volume source for the pin using the actual tool dimensions. Based on the work of Chao et al., ${ }^{23,24}$ the distribution of the heat flux under the tool shoulder $q_{\mathrm{s}}$, was taken to vary linearly with angular velocity according to

$$
q_{\mathrm{s}(\mathrm{r})}=\frac{3}{2 \pi} \frac{Q_{\mathrm{s}} r}{R_{\mathrm{s}}^{3}-R_{\mathrm{p}}^{3}} \text { for } R_{\mathrm{P}} \leqslant r \leqslant R_{\mathrm{S}}
$$

where $R_{\mathrm{s}}$ and $R_{\mathrm{p}}$ are the dimensions of the shoulder and pin and $r$ is the radial distance. The heat input from the pin was assumed to be uniform with the pin depth. As in the authors' original mechanical tensioning paper, ${ }^{17}$ the power for the tool heat source was first estimated on the basis of a computational fluid dynamics (CFD) model, developed by Colegrove and Shercliff. ${ }^{25-28}$ The CFD model is capable of predicting the heat input from the tool geometry and welding conditions. Simulations obtained from the FE model were then compared to thermocouple responses and the model iterated slightly until an accurate fit was obtained.

\section{Heat sink representation}

The cooling system represented in the simulations corresponds to that originally developed by BAE Systems and involves semisolid $\mathrm{CO}_{2}$ snow applied via a spray to the plate surface (Fig. 1). Cooling occurs by heat conduction across the plate surface exploiting the latent heat of sublimation. Application of the coolant is kept within a circular inner $25 \mathrm{~mm}$ nozzle, which is surrounded by a concentric sleeve having a rubber seal to extract the gas generated. Early experimental trials ${ }^{29}$ indicated the cooling power of this nozzle to be approximately $-800 \mathrm{~W}$ at $20^{\circ} \mathrm{C}$. The cooling source was included in the FE model as a uniform convective heat flux $q_{\mathrm{c}},{ }^{27}$ acting over a circular surface $(25 \mathrm{~mm}$ diameter), given by

$$
q_{\mathrm{c}}=h_{\mathrm{c}}\left(T-T_{\min }\right)
$$

where $T_{\min }$ was set to the boiling temperature for $\mathrm{CO}_{2}$ $\left(-72^{\circ} \mathrm{C}\right)$, and $h_{\mathrm{C}}$ is the interfacial heat transfer coefficient. Assigning a representative value for $h_{\mathrm{C}}$ is problematical since it is influenced by several factors including weld temperature, ambient temperature, traverse speed and heat sink area. However, many of these parameters change with welding conditions, and therefore experimental calibration is essential. It should be noted that $h_{\mathrm{C}}$ also depends on the amount of gas evolved, which can act as an insulating layer at the interface. 

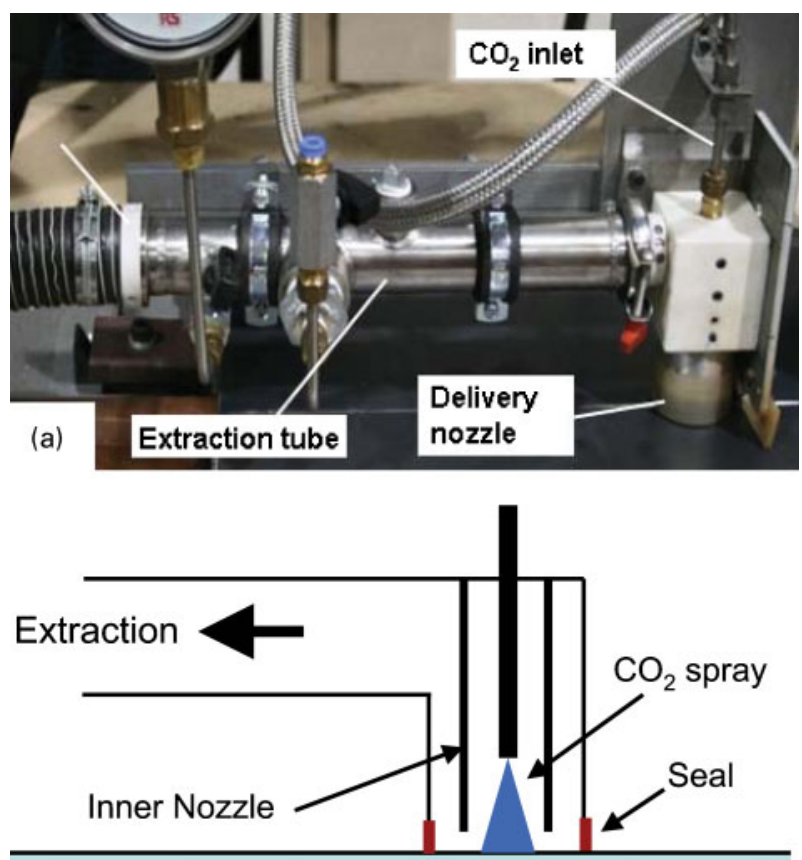

(b)

1 a photograph and $b$ schematic of self-extracting cryogenic cooling system ${ }^{29}$ showing nozzle design with concentric shroud to allow extraction of gas generated (important for arc welding applications)

\section{Heat source calibration experiments}

Key to improving our understanding of thermal tensioning is the realistic representation of the heat sink or sinks. To this end, instrumented experimental trials of stationary and moving cooling nozzles were undertaken using the arrangement described above and shown in Fig. 1.

\section{Stationary heat sink}

Experiments were carried out by applying a stationary heat sink to a cylindrical AA 2024-T3 plate of dimensions $150 \mathrm{~mm}(\phi) \times 25 \mathrm{~mm}$ (thickness) having a $50 \mathrm{~mm}$ $(\phi) \times 3.2 \mathrm{~mm}$ (thickness) central web. The plate was preheated to a series of temperatures $(350,250$ and $100^{\circ} \mathrm{C}$ ) in a furnace before removal and the cooling nozzle directed at the centre of the top surface. The cooling rate was measured using thermocouples positioned on the underside of the central web. The experimental set-up was then simulated by an FE model, to obtain the best fit for the interfacial heat transfer coefficient. The best fit occurred for an interfacial heat transfer coefficient of $h_{\mathrm{c}}=3 \cdot 7 \mathrm{~kW} \mathrm{~m}^{-2} \mathrm{~K}^{-1}$ (Fig. 2a). This equates to a cooling power of $-166 \mathrm{~W}\left(q_{\mathrm{c}}=\right.$ $-0.337 \mathrm{MW} \mathrm{m}^{-2}$ ) at $20^{\circ} \mathrm{C}$, much lower than the $-800 \mathrm{~W}$ expected for the nozzle on the basis of previous welding experiments using this cooling set-up. ${ }^{29}$ By contrast, it is larger than the maximum value $\left(2 \mathrm{~kW} \mathrm{~m}^{-2} \mathrm{~K}^{-1}\right)$ obtained by van der Aa et al. ${ }^{15}$ for a simple free liquid $\mathrm{CO}_{2}$ jet applied to steel. That jet equates to a power of just $-90 \mathrm{~W} \quad\left(q_{\mathrm{c}}=\right.$ $-0.184 \mathrm{MW} \mathrm{m}^{-2}$ ) at $20^{\circ} \mathrm{C}$ for the same area. One possible reason for the low cooling power associated with a static nozzle is that the gas evolved creates an insulating layer at the interface thereby limiting the rate of heat loss.

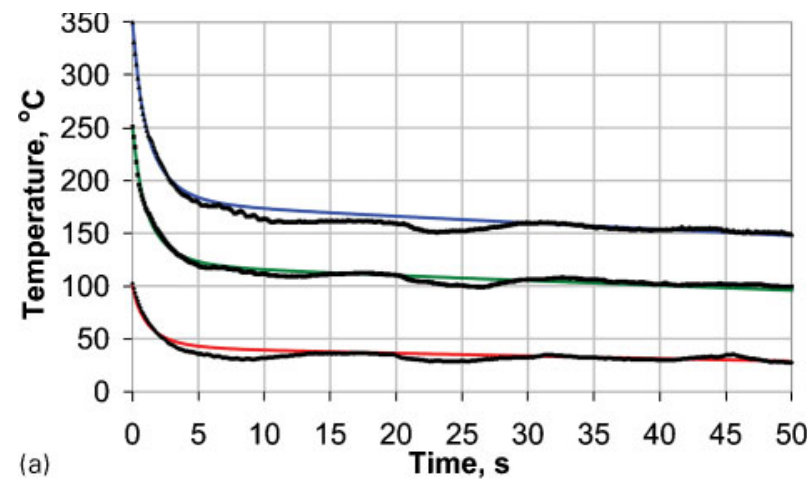

(a)

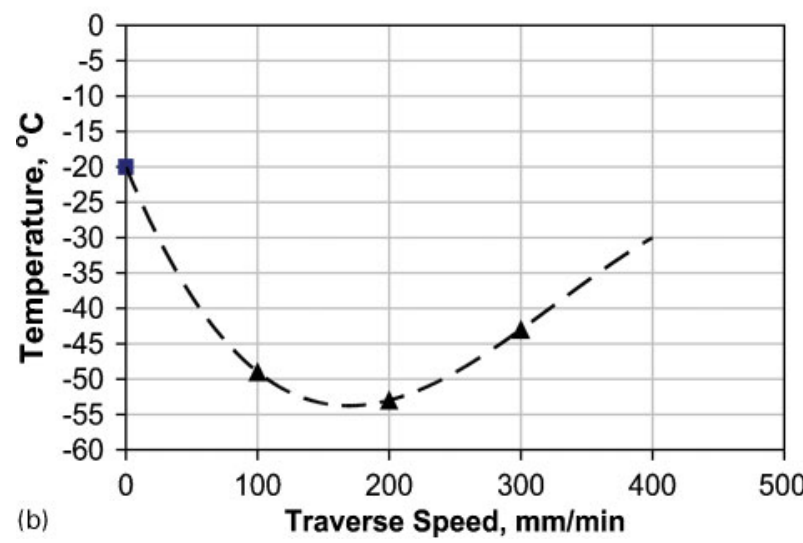

2 Stationary $\boldsymbol{a}$ and moving $\boldsymbol{b}$ cooling nozzle calibration trials; a showing the thermal history at the centre of a stationary plate pre-heated to $350^{\circ} \mathrm{C}, 250^{\circ} \mathrm{C}$ and $100^{\circ} \mathrm{C}$, (measurements thick, simulation thin lines with best fit $\mathrm{h}_{\mathrm{c}}=3.7 \mathrm{~kW} \mathrm{~m}^{-2} \mathrm{~K}^{-1}$ ); $\mathrm{b}$ the minimum temperature as a function of traverse speed with a room temperature plate (measurements dashed line, symbols simulations with fitted $h_{c}$ values given in Table 1)

\section{Moving heat sink}

Experiments with a moving heat sink were undertaken with the nozzle applied to a $350 \times 250 \times 3 \cdot 2 \mathrm{~mm}$ (thickness) AA 2024-T3 plate without any preheating. Three typical FSW traverse speeds were selected, namely 100, 195 and $300 \mathrm{~mm} \mathrm{~min}^{-1}$. Thermocouples placed at 0,5 , 10 , and $20 \mathrm{~mm}$ distances from the weld line were used to measure the thermal profile in each case. The data from these three experiments are summarised in Table 1 and Fig $2 b$ alongside the result form the static test.

Figure $2 b$ shows that the lowest temperature reached for each traverse speed is a strong function of the traverse speed. This required a different value of $h_{\mathrm{c}}$ for each traverse speed in order to obtain a reliable fit and the optimised values are shown in Table 1. Encouragingly, the maximum cooling effect was observed at a travel speed close to that used in the BAE Systems trials $\left(195 \mathrm{~mm} \mathrm{~min}^{-1}\right)$ for which $h_{\mathrm{c}}=$ $16 \mathrm{~kW} \mathrm{~m}^{-2} \mathrm{~K}^{-1}$. This is equivalent to a cooling power of $-736 \mathrm{~W}$ at $20^{\circ} \mathrm{C}$, which is similar to the value suggested by the original BAE trials.

Table 1 Minimum temperature measured for each of moving sink experiments alongside best fit values of $h_{\mathrm{c}}$ for fit with FE model

Traverse speed, $\mathrm{mm} \mathrm{min}^{-1} \quad 0 \quad 100 \quad 195300$

Measured minimum temperature, ${ }^{\circ} \mathrm{C} \quad-20 \quad-50 \quad-54 \quad-43$

$\begin{array}{lllll}\text { Inferred } h_{\mathrm{c}}, \mathrm{kW} \mathrm{m}{ }^{-2} \mathrm{~K}^{-1} & 3 \cdot 7 & 12 & 16 & 8\end{array}$ 


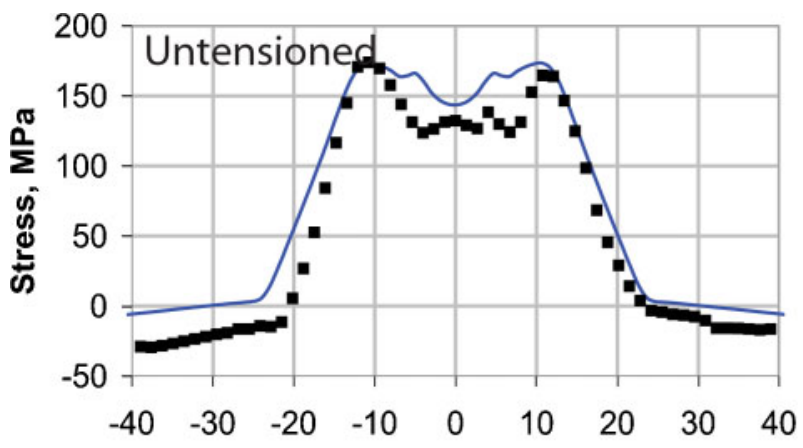

(a)

Distance from weld line, $\mathrm{mm}$

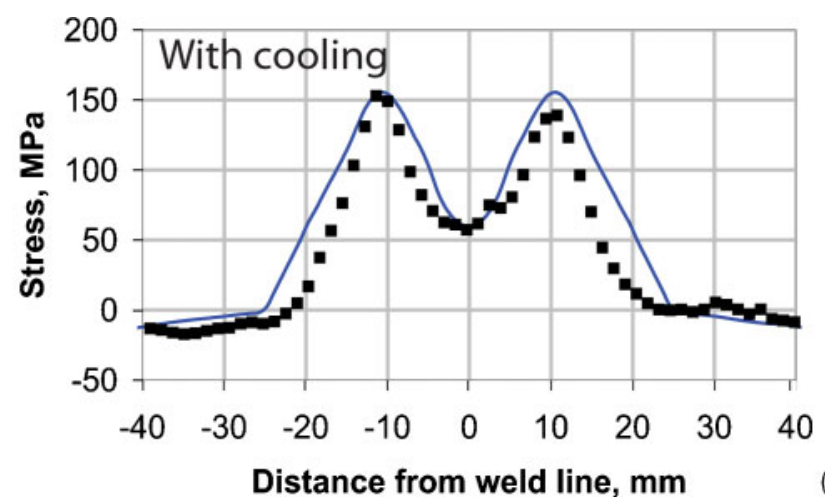

(b)

$3 d_{0}$ corrected (assuming plane stress) longitudinal residual stresses measured by neutron diffraction (symbols) at midthickness half-way along a welded AA2024-T3 sheet, taken from ${ }_{7}{ }_{7}$, compared with the best-fit FE model (lines); a without cooling, and $b$ with local $\mathrm{CO}_{2}$ cooling applied. Only the central sections $(\sim 30 \%)$ are shown for clarity, welding speeds of $355 \mathrm{rpm}$ and $95 \mathrm{~mm} / \mathrm{min}$ were used in both cases

It is noticeable in Table 1 that at low speeds, $h_{\mathrm{c}}$ increases sharply before becoming approximately constant at higher traverse speeds, where the increasing speed of the nozzle reduces the time per unit area for heat extraction, as noted above. The rapid rise in cooling efficiency on accelerating from the static condition corroborates the earlier hypothesis that the ineffectiveness of a stationary sink arises from a combination of gas and $\mathrm{CO}_{2}$ snow building up beneath the cooling nozzle, so as to form an insulating layer that reduces the rate of heat loss.

\section{Experimental validation}

Few DC-LSND trials with reliable residual stress measurements have been described in the literature for FS welding aluminium alloys. Indeed, it seems that the only FSW trials for which residual stresses have been measured are those of BAE Systems, ${ }^{14,16}$ in which two AA 2024-T3 plates $[380 \times 125 \times 6.3 \mathrm{~mm}$ (thickness)] were butt FS welded (rotation, $355 \mathrm{rev} \mathrm{min}^{-1}$; traverse speed, $95 \mathrm{~mm} \mathrm{~min}^{-1}$ ) with and without local cooling. In these early experiments liquid $\mathrm{CO}_{2}$ was simply sprayed onto the welded plates through two pipes positioned close to the rear of the tool. This arrangement delivered cooling to the plate approximately 30 to $40 \mathrm{~mm}$ behind the tool. This approach, although crude, provided sufficient local cooling to show measurable differences in the subsequent residual stress fields, as measured by Staron et al. ${ }^{16}$ (Fig. 3). Here the diffraction data from the original experiments ${ }^{16}$ were corrected for instrument and solute related unstrained lattice parameter $d_{0}$ effects (by assuming plane stress conditions). ${ }^{30}$ In the figure only the central (predominantly tensile) section of the plates are shown; both the measurements and the modelled stresses satisfy stress balance across the full width of the plate. The residual stresses for the untensioned weld exhibit the widely observed, ${ }^{2,31}$ and previously explained, ${ }^{17} \mathrm{M}$ shaped residual stress profile. It is evident that active cooling brings about a large reduction in the longitudinal residual stresses at the weld line $(\sim 60 \%)$, along with a more modest effect on the peak stresses located within the HAZ $(\sim 15 \%)$.

Unfortunately the welds were not fully instrumented, nor was the coolant source capability quantified. In the absence of thermal calibration data, the tool was simulated here using a power of $1350 \mathrm{~W}$, estimated using the CFD model developed by Colegrove. ${ }^{25}$ For the thermal tensioning experiment the best match to the data was obtained using a value for the interfacial heat transfer coefficient $h_{\mathrm{c}}$, of $16 \mathrm{~kW} \mathrm{~m}{ }^{-2} \mathrm{~K}^{-1}$ (equivalent to a cooling power of $-736 \mathrm{~W}$ at $20^{\circ} \mathrm{C}$ ) using the above $25 \mathrm{~mm}$ heat sink to represent the overlapping delivery of the two pipes at a distance of $40 \mathrm{~mm}$ behind the tool. In accordance with the experiments, thermal tensioning is predicted to significantly reduce the centreline stress, but to have less effect on the peak stresses in the HAZ. Given the uncertainties in the definition of the cooling system, there is a surprisingly good fit between the measured and simulated results for the case of thermal tensioning (Fig. 3b). This may be a consequence of the observation made by van der $\mathrm{Aa}^{32}$ that more sophisticated distributed cooling sinks give similar predicted residual stresses to very simple uniform cooling when applied over an equivalent area. Either way, it suggests that the authors' cooling model is delivering a level of cooling of the right ball park, certainly it is sufficiently realistic to allow a systematic examination of the relative merits of different thermal tensioning strategies.

\section{Optimisation trials and discussion}

Given that the authors' heat sink trials and the previous welding trials are in accordance with a heat sink capability of $\sim 16 \mathrm{~kW} \mathrm{~m}^{-2} \mathrm{~K}^{-1}$, the authors will now use the thermal weld to investigate a range of cooling strategies. For these simulations the plate geometry, alloy condition and welding parameters were kept the same as those used in previous global mechanical tensioning experiments carried out by the authors. ${ }^{17}$ As a result, the same accurately calibrated heat source could be used. It has already been validated for a traverse speed of $195 \mathrm{~mm} \mathrm{~min}{ }^{-1}$ and a rotation speed of

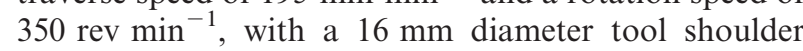
and a $5 \mathrm{~mm}$ diameter pin. Fortuitously, this traverse speed corresponds closely to the optimum identified in Table 1 for heat extraction using the current nozzle arrangement. Unless specified otherwise the maximum cooling capacity $\left(h_{\mathrm{c}}=16 \mathrm{~kW} \mathrm{~m}{ }^{-2} \mathrm{~K}^{-1}\right)$ of the nozzle is used in the simulations; however, that corresponding to the stationary source $\left(h_{\mathrm{c}}=3.7 \mathrm{~kW} \mathrm{~m} \mathrm{~K}^{-1}\right)$ is considered as a lower bound on specific occasions below. 

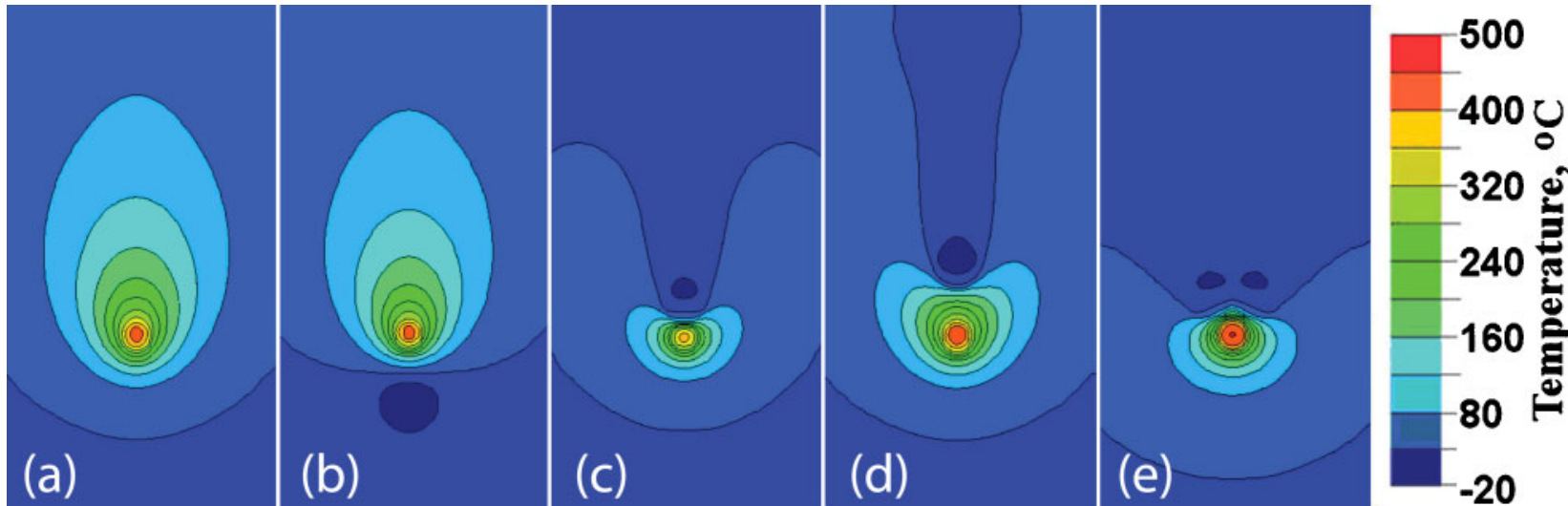

4 The effect of placing a cooling source of maximum intensity at various locations relative to the FSW tool (moving down page) operating at of $350 \mathrm{rpm}$ and $195 \mathrm{~mm} / \mathrm{min}$; $a$ no heat sink, $b$ heat sink $20 \mathrm{~mm}$ ahead of the tool $c$ heat sink $20 \mathrm{~mm}$ behind the tool $d$ heat sink $40 \mathrm{~mm}$ behind the tool. For clarity only the central $100 \mathrm{~mm}$ of the $250 \mathrm{~mm}$ width of the welded plates is shown

\section{Effect of nozzle location}

There are a number of simple options for the placement of the heat sink in dynamic thermal tensioning, some of which are illustrated in Fig. 4. From this, it is immediately evident that placement of a heat sink ahead of the tool, even when as close as possible and with the maximum cooling intensity, is relatively ineffective at modifying the thermal field. By comparison, a heat sink placed close behind the tool (Fig. 4c) drastically modifies the local thermal field, although the effect falls off rapidly with increasing the standoff distance (Fig. 4d). On a more quantitative level, Fig. $5 a$ shows the effect on the thermal profile when the nozzle is placed at a centre to centre distance of only $20 \mathrm{~mm}$ behind the tool. In reality it is probably not practical to place the nozzle quite so close, unless the cooling system is integrated into the design of the welding head. Nevertheless, it is indicative of the maximum effect that could be expected using a local cryogenic cooling system. In comparison Fig. $5 b$ shows the much less marked effect of placing the heat sink at a more conservative distance of $40 \mathrm{~mm}$ from the tool.

Perhaps unsurprisingly given the thermal profiles, placing the nozzle as close as possible behind the heat source has a dramatic effect on the development of stress in the hot (soft) material emerging from behind the weld tool, as shown in Fig. $6 a$. For clarity, only the central section of the weld is shown; the stresses in the parent plate become increasingly compressive towards the edges as seen in Ref. 17 for the uncooled case. With the nozzle $20 \mathrm{~mm}$ behind the tool, the original weld line longitudinal tensile stresses of $\sim 140 \mathrm{MPa}$ are actually reversed and replaced by a compressive stress $(\sim 20 \mathrm{MPa})$ with the stresses in the HAZ reduced by $\sim 60 \%$. Unsurprisingly, with the heat sink placed $40 \mathrm{~mm}$ behind the tool the effects are reduced, although a $70 \%$ reduction in the weld line longitudinal tensile stresses is still achieved. Reducing the cooling power of the heat sink also has a marked effect on the stress profiles, as demonstrated by comparing Fig. $6 a$ and $b$. These trends are summarised in Fig. 7, illustrating the importance of minimising the distance between the cooling source and the FSW tool and the maximising the cooling power of the nozzle. For cooling nozzles placed further than $\sim 80 \mathrm{~mm}$ from the tool, it is apparent from Fig. 7 that there is only a modest reduction in residual stresses and little difference between the results for the upper and lower bound cooling. In Fig. 8 the efficacy of placing the nozzle in front of the tool is compared with its placement behind the tool. These results confirm that a leading heat sink is much less effective in modifying the thermal field and reducing the residual stresses.

\section{Effect of cooling power}

The effect of cooling efficiency of the nozzle on the peak and weld line residual stresses is shown in Fig. 9. This shows diminishing returns are achieved by increasing the

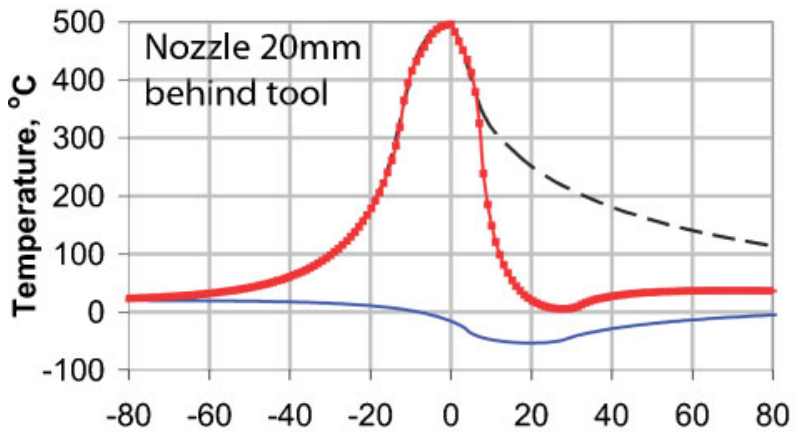

(a)

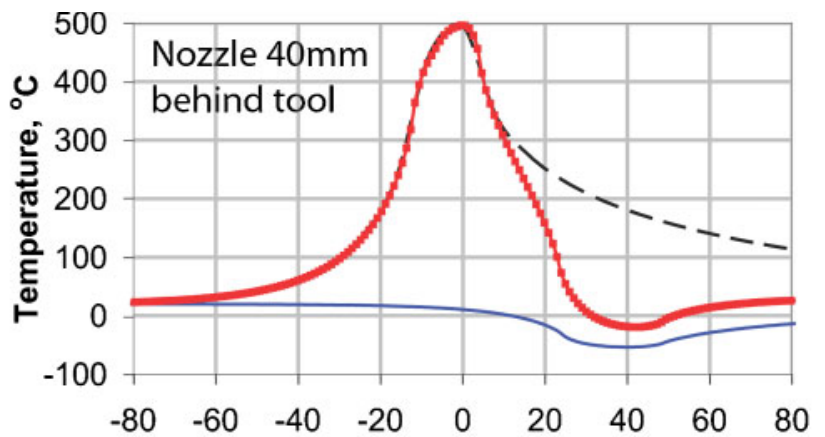

Distance from weld tool, $\mathrm{mm}$ (b)

5 Thermal profiles along the weld line through the welding tool heat source for $a$ the Nozzle $20 \mathrm{~mm}$ behind tool and $b$ the Nozzle $40 \mathrm{~mm}$ behind tool; with cooling (squares-line) without cooling (dashed line), as well as for the application of the cooling nozzle on its own (thin solid line) 

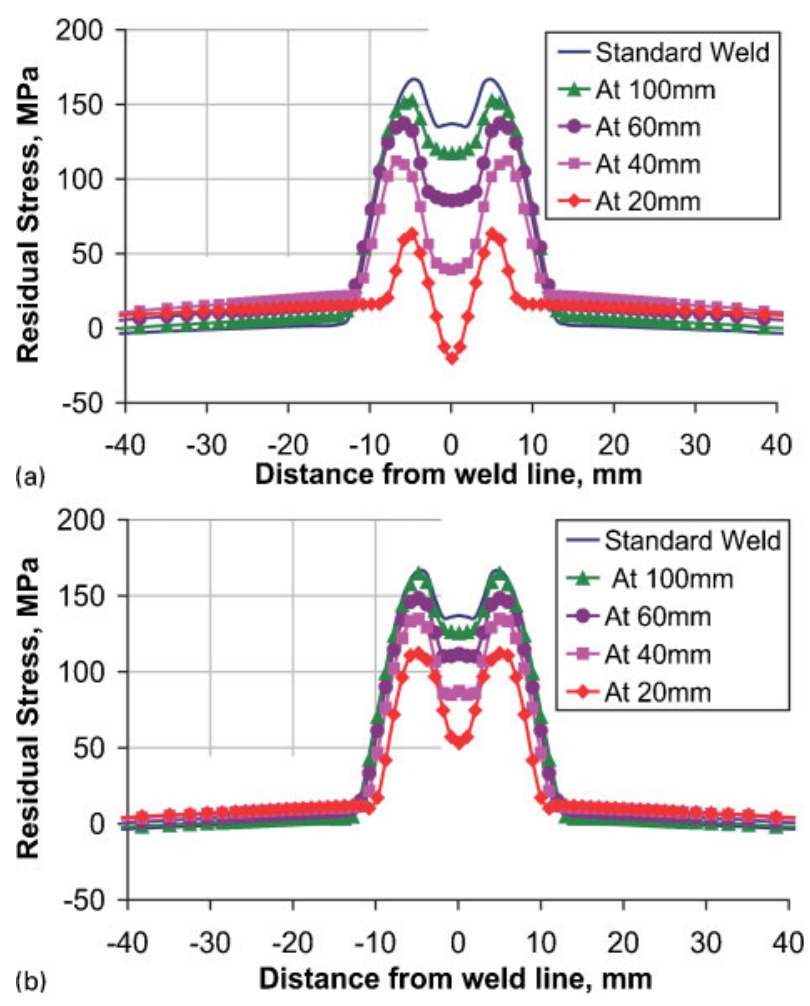

6 Predicted longitudinal residual stress profiles predicted across the weld at mid thickness halfway along the welded AA2024-T3 plates using with, a Maximum cooling strength $b$ minimum cooling strength; with a nozzle placed 20, 40, 60 and $100 \mathrm{~mm}$ (line and points) behind the tool. The thin solid line is for a standard weld without cooling. The FSW simulated was produced at $350 \mathrm{rpm}$ and $195 \mathrm{~mm} / \mathrm{min}$. Only the central $30 \%$ of the welds are shown

cooling power much beyond $400 \mathrm{~W}$ at $20^{\circ} \mathrm{C}$. Van der Aa et al. ${ }^{15,32}$ and $\mathrm{Li}^{33}$ have looked into the positioning and power of heat sinks in DC-LSND and found them to be the most important factors for maximising the relief of residual welding stresses. $\mathrm{Li}$ also postulated that there would be limited further benefits above a certain cooling intensity. On the basis of water jet cooling during gas tungsten arc welding of titanium, Li proposed that a

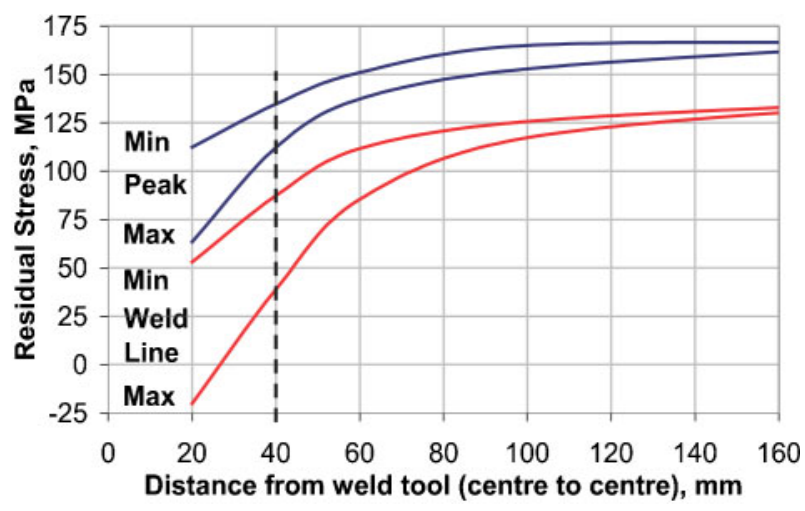

7 The effect of cooling nozzle location on the longitudinal residual stresses at the weld line and the peak values seen at the TMAZ/HAZ boundary corresponding to the upper and lower bounds for nozzle cooling strength. The dashed line represents the nozzle at a stand-off distance of $40 \mathrm{~mm}$ and is referred to in the text

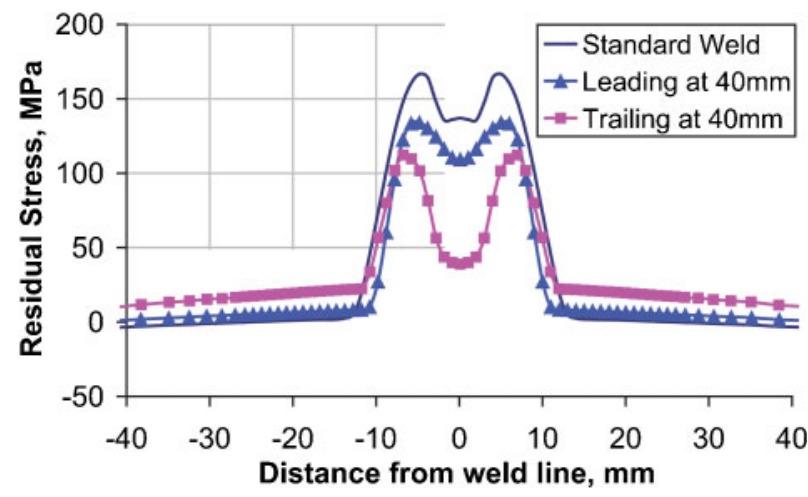

8 Comparison of predicted longitudinal residual stress profiles, at midthickness halfway along welded AA 2024-T3 plates, without cooling (line), and with cooling nozzle $40 \mathrm{~mm}$ in front of tool (line and triangles) and $40 \mathrm{~mm}$ behind tool (line and squares)

ratio of $60 \%$ between the heat removed by the sink and the heat input by the welding process, might be optimal for other welding conditions. This criterion (indicated by the vertical broken line in Fig. 9) would appear to be supported by the authors' results.

\section{Mechanism of local thermal tensioning}

In order to better understand the mechanism of local thermal tensioning, it is helpful to study the evolution of the thermal and stress fields during welding. In simple terms tensile stresses normally arise because a compressive plastic misfit is introduced in the near weld region ahead and under the tool where the metal is hot and thus expanded and very soft. As a result, a large negative misfit develops due to thermal contraction on cooling, which generates tensile longitudinal stresses at the weld line behind the tool as the yield stress increases with falling temperature (Fig. 10a). These stresses are balanced by far field compressive stresses near the plate edges, which can cause buckling of thin sheets. ${ }^{34,35}$

The distribution of longitudinal stress along the weld line is plotted in Fig. 10 for cooling nozzles placed in front of and behind the tool. When applying a cooling nozzle it should be borne in mind that it has two counteracting effects; first the associated thermal contraction can introduce tensile misfits. Second, because it

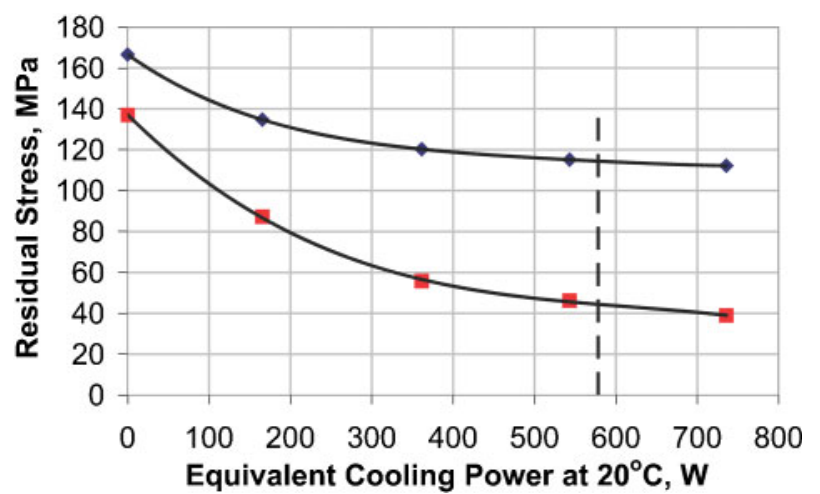

9 Effect of cooling intensity on longitudinal stress at weld line (squares and line) and peak values at edge of HAZ (line and diamonds), for welded AA 2024-T3 plates, all using welding parameters of $350 \mathrm{rev} \mathrm{min}^{-1}$ and $195 \mathrm{~mm} \mathrm{\text {min}^{-1 }}$ using heat sink $40 \mathrm{~mm}$ behind tool: see main text for significance of broken line 

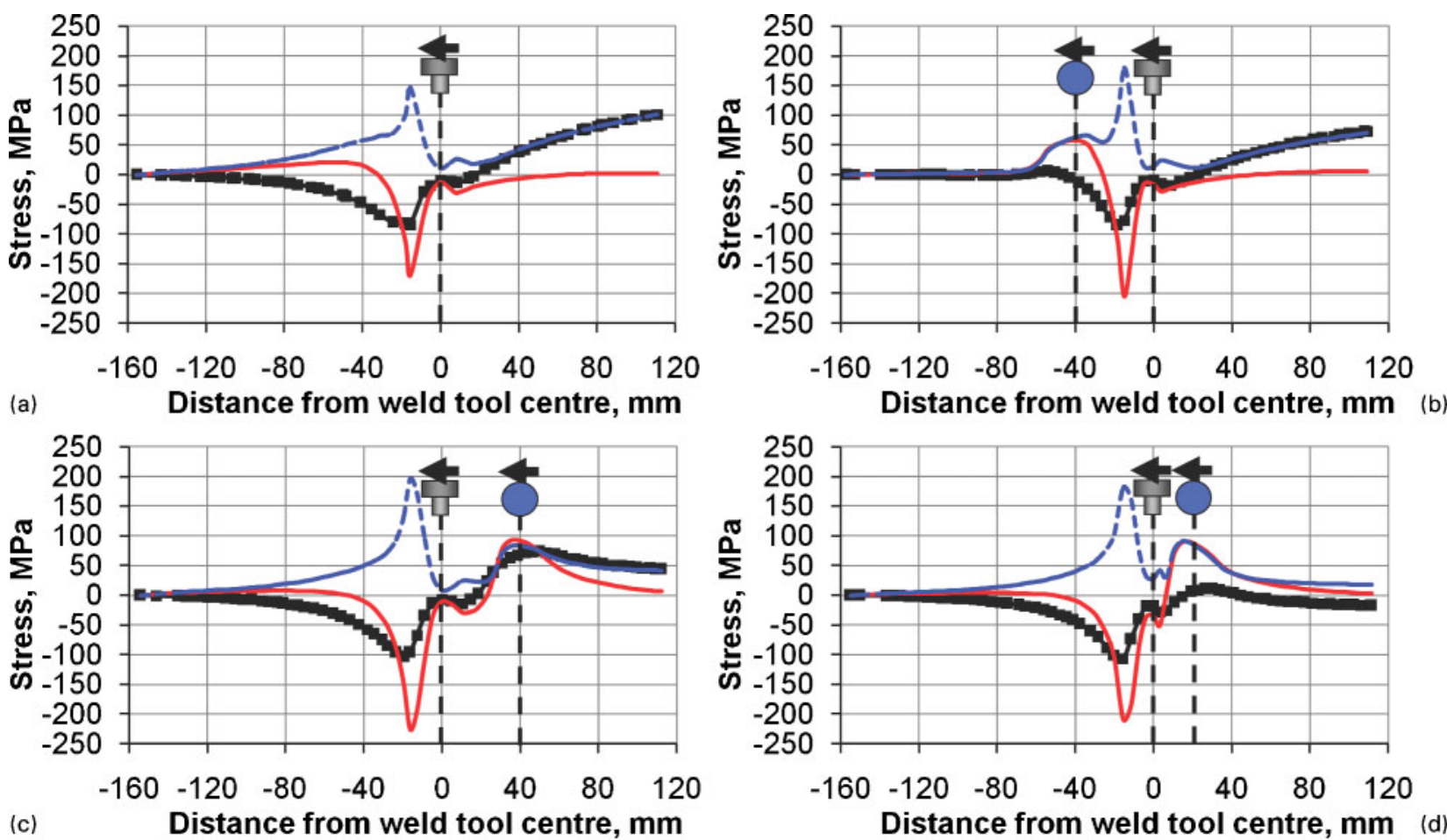

10 Predicted development of the longitudinal (lines and squares), transverse (lines), and Von Mises (dashed line) stresses with distance along the weld line relative to the tool position for welding parameters of $350 \mathrm{rpm}$ and $195 \mathrm{~mm} / \mathrm{min}$ assumed in all cases; a no cooling, $b$ nozzle $40 \mathrm{~mm}$ ahead of tool, $c$ Nozzle $40 \mathrm{~mm}$ behind tool, $d$ Nozzle $20 \mathrm{~mm}$ behind tool

lowers the temperature locally, it tends to increase the yield stress requiring larger stresses to introduce such plastic misfits.

Cooling should be considered ahead of the tool. As noted in connection with Fig. 4, due to the forward motion of the tool the associated thermal field extends further in its wake. Consequently, the nozzle would need to be very close to the tool so as to tension the weld in a region where it is hot enough (soft) to significantly influence the longitudinal stresses. Placing the heat sink ahead of the tool also precools the plate slightly reducing the temperature under the tool (this may of course cause the FSW unit to put more energy into the tool offsetting any benefit somewhat). This is equivalent to reducing the tool power, which moderately reduces the width of the HAZ and moves the peak stresses slightly inwards (Fig. 8). Both of these effects can be seen in the simulations (Fig. 10b). The compressive bow wave occurs somewhat closer to the tool, when the leading heat sink is present, the peak stresses being slightly higher due to the lower temperatures (higher yield stress). Overall, however, the benefits to the final residual stress distribution are limited.

To obtain a better picture of the stress relief process for a trailing nozzle it is helpful to study the evolution of the longitudinal stresses across the weld line for a given location as a function of time (Fig. 11). The compressive bow wave as the tool approaches is clear in Fig 11a. By the time the tool is within $16 \mathrm{~mm}$ all the material within $25 \mathrm{~mm}$ laterally of the weld line has reached the yield locus (Fig. 11b), aided by the large transverse stresses (see Fig. 11) and by the great fall in yield stress due to the increasing temperature. This compressive straining becomes increasingly easy as the tool passes over, because the yield stress drops essentially to zero at temperatures above $450^{\circ} \mathrm{C}$ (Fig. $11 c$ and $d$ ). The compressive misfit thus generated is very important because, unless removed, it will ultimately lead to tensile residual stresses.

Just after the tool has passed over, longitudinal tensile stresses begin to develop as the weld material contracts as it begins to cool (Fig. 11e). Normally the stresses remain below the yield stress throughout cooling, such that most of the compressive longitudinal misfit introduced before the tool passing over is retained on cooling. Addition of active cooling increases both the longitudinal and transverse tensile stresses between the tool and the nozzle (Fig. 11d and $e$ ), initiating considerable tensile yielding due to the very low tensile yield stress of the hot metal close to the rear of the tool. It is the steep valley profile of the yield locus laterally in Fig. 11 that prevents tensile plastic yielding further from the weld line and leads to the formation of the pronounced and characteristic $M$ shaped stress profile typically observed for thermal tensioning (see Fig. 6). Once the nozzle has passed over (Fig. 11f), the metal is too cold for further significant yielding. From this point onwards, 'the die is cast' and no further plastic misfit is introduced so that the stresses simply re-equilibrate as the plate cools elastically. Well behind the tool (Fig. 11g), the stress development in the untensioned plate lags the tensioned one, simply because its rate of cooling is slower.

To maximise the tensile straining around the trailing edge of the tool (Fig. 11d), the nozzle should be as close as practically possible to the tool. In other words, tensioning works best when significant tension is applied to the hot material emerging from under the tool where it has a near zero flow stress. Previously the cooling behaviour has been said to change depending on 

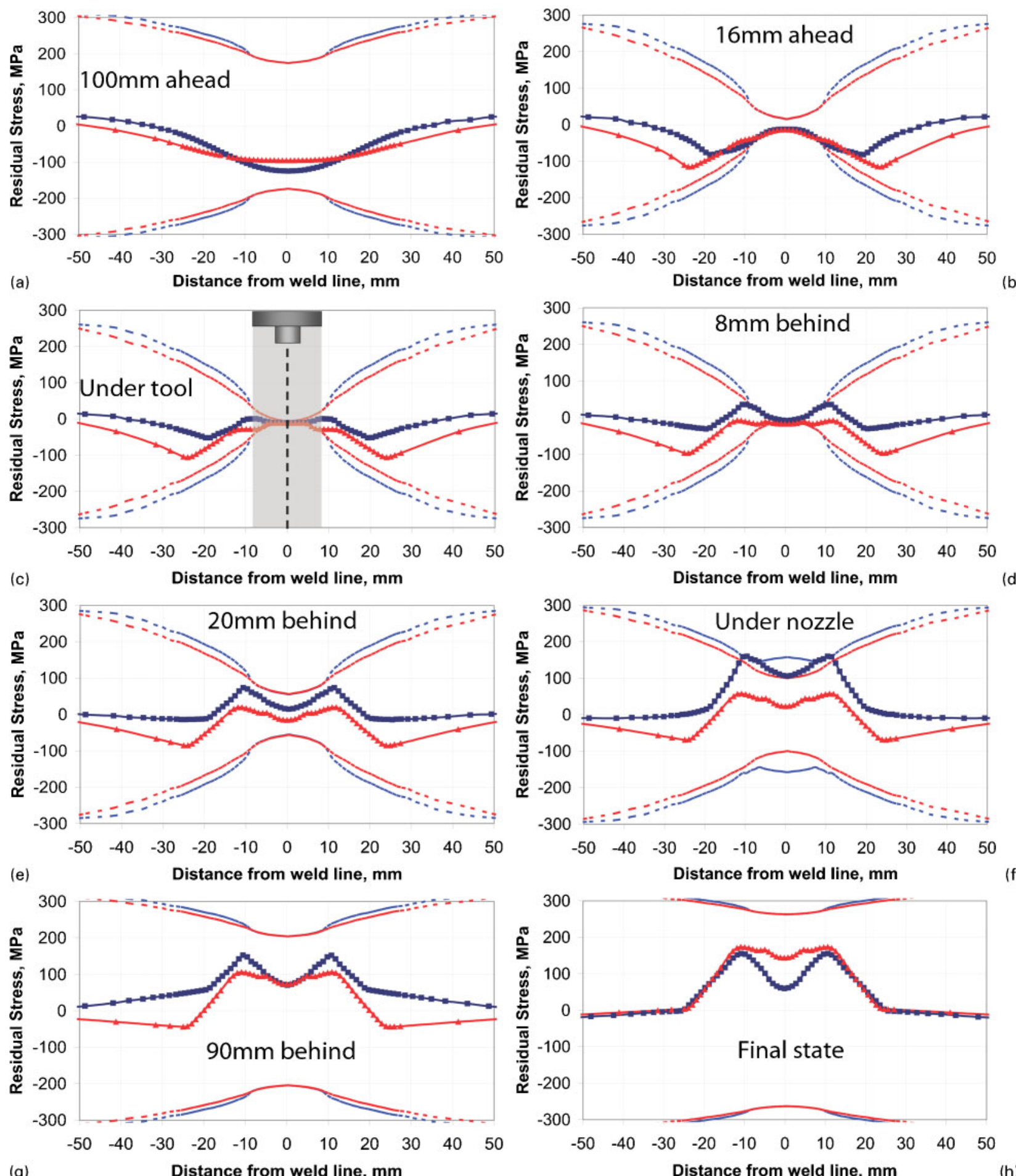

(g)

Distance from weld line, $\mathrm{mm}$

(h)

11 Predicted longitudinal residual stress profiles across the mid-thickness of the weld for a nozzle trailing 40 mm distance behind the tool (line and squares) compared to that for a standard weld without cooling (red line and triangles) alongside the temperature dependent tensile and compressive yield loci (respective dashed lines) for welding parameters were $350 \mathrm{rpm}$ and $195 \mathrm{~mm} / \mathrm{min}$; $a 100 \mathrm{~mm}$ ahead of the tool, $b 16 \mathrm{~mm}$ ahead of the tool, $c$ under the tool, $d$ $8 \mathrm{~mm}$ behind the tool e $20 \mathrm{~mm}$ behind the tool, $f$ under the heat sink at $40 \mathrm{~mm}, g 90 \mathrm{~mm}$ behind the tool and $h$, the final residual stress state

whether it is sufficiently intense to split the rear of the thermal field. ${ }^{32}$ However, this behaviour is probably more attributable to the proximity of the heat sink to the trailing edge and its effect on the soft material trailing the tool.

\section{Two cooling nozzle strategies}

In view of the evolution of stress plotted in Fig. 11, it is worthwhile asking whether one could lower the peak residual stresses in the HAZ region using two sinks displaced at either side of the weld line in an attempt to generate greater tensile plasticity there. In order to investigate this possibility, two $25 \mathrm{~mm}$ heat sinks were placed as close as possible behind the tool $(\sim 20 \mathrm{~mm})$. Their lateral spacing was chosen such that the heat sinks were placed directly over the TMAZ/HAZ and were touching at the weld line. The presence of two cooling nozzles removes the horseshoe shape of the 


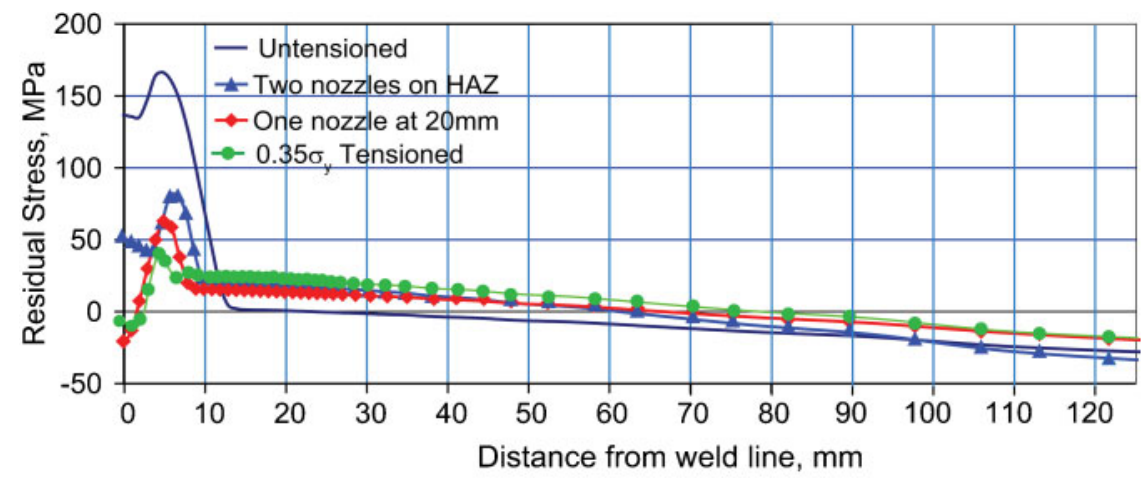

12 Longitudinal stress profiles comparing effect of no heat sinks, two nozzles side by side $20 \mathrm{~mm}$ behind tool and one nozzle placed $20 \mathrm{~mm}$ behind tool with global tensioning to $0.37 \sigma_{\mathrm{y}}(120 \mathrm{MPa})$ : in all cases welding parameters of

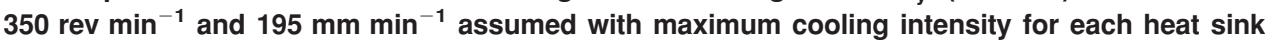

instantaneous thermal field (Fig. 4e). Nevertheless, it is not as effective as the single cooling nozzle in lowering the peak stresses in the HAZ, despite the enhanced cooling from the greater sink area (Fig. 12). This is primarily because the tensile plastic stresses generated by the heat sinks placed on the HAZ are being applied to a region that is significantly stronger (colder) than the corresponding location on the weld line. These simulations thus suggest that it is not possible to modify the thermal field under the trailing edge of the tool sufficiently, using practically achievable side by side cooling nozzle arrangements, to completely remove the tensile stress peaks in the HAZ, and the best that can be achieved is around a $50-60 \%$ reduction.

\section{Comparison with global mechanical tensioning}

It is worthwhile comparing local thermal tensioning with global mechanical tensioning (described in detail elsewhere), ${ }^{2,3,17}$ the effectiveness of which is well documented, ${ }^{21}$ since the former has certain practical advantages. Both introduce tensile strains in the soft region immediately after the tool has passed that reverse the compressive misfit introduced before its passing. Global mechanical tensioning tends to be more effective (see Fig. 12), primarily because it tensions the entire plate, and therefore is guaranteed to influence the stresses underneath and close to the tool where the material is softest. In comparison, introducing tensile straining in the hot zone is more difficult than active cooling. This is both because of difficulties in placing the nozzle close enough and because the nozzle itself cools the plate raising the yield stress. In spite of these challenges, the difficulty of applying large tensile forces to the weld region for global tensioning for all but the simplest of welding geometries means that thermal tensioning by active cooling probably has a greater potential for widespread practical application.

\section{Conclusions}

The authors have used an FSW FE model for which the softening response of AA 2024 and the overall residual stresses have been validated against experiment in order to investigate the efficacy of different active cooling strategies. The authors' simulations have been validated both by cooling calibration experiments and comparison with available thermal tensioning experiments. The results of the authors' simulations and practical heat sink experiments have shown the following.
1. There is an optimal operating window for the welding traverse speed at which the maximum cooling from the heat sinks is achieved practically. This is dictated by the flow rate and nature of the cooling medium, its extraction/removal and the speed of conduction/heat loss from the weld material. In the present case, the optimum speed was $\sim 200 \mathrm{~mm} \mathrm{~min}^{-1}$, which fits well to practical FSW speeds.

2. Cooling nozzles placed in front of the tool had very little effect on the final residual stresses.

3. Trailing nozzles were able to bring the material between the tool and nozzle to the tensile yield locus thereby reducing the compressive misfit introduced ahead/under the tool. As the plate is the softest near the trailing edge of the tool, this is where the greatest effect of placing a heat sink is achieved.

4. The largest reduction in tensile residual stress was achieved on the weld line, with compressive stresses predicted using high cooling powers applied very close to the weld tool. For a more conservative placement of the cooling nozzle the weld line residual stresses could still be reduced by $\sim 80 \%$.

5. While it was found that the tensile peak stresses located at the HAZ/TMAZ boundary could be reduced by up to $50 \%$ with a trailing heat sink, they could not be reduced further under the conditions studied, due to the higher strength of the (colder) material lateral to the weld. No improvement was found for two cooling nozzles placed side by side.

6. For the range of parameters investigated, little benefit is foreseen by cooling in excess of about 60 to $70 \%$ of the welding power. This is in accordance with the ratio proposed by $\mathrm{Li}^{33}$ for thermal tensioning of gas tungsten arc welds.

These simulation studies suggest that active local cooling has potential for practical application in industry as a means of limiting weld residual stresses. Further experimental trials should focus on the placement of a single nozzle as close as possible to the trailing edge of the tool.

\section{Acknowledgements}

The authors would like to thank A. Wescott of BAE Systems for the provision of data and samples. This work is supported through the University of Manchester EPSRC Light Alloys Portfolio Partnership (grant no. EP/D029201/1) in collaboration with Airbus UK and BAE Systems. 


\section{References}

1. P. L. Threadgill, A. J. Leonard, H. R. Shercliff and P. J. Withers: 'Friction stir welding of aluminium alloys', Int. Mater. Rev., 2009. 54, (2), 50-93.

2. M. Peel, A. Steuwer, M. Preuss and P. J. Withers: 'Microstructure, mechanical properties and residual stresses as a function of welding speed in aluminium AA5083 friction stir welds', Acta Mater., 2003, 51, 4791-4801.

3. P. Staron, M. Koçak, S. Williams and A. Wescott: 'Residual stress in friction stir-welded Al sheets', Physica B, 2004, 350B, (1-3), E491-E493.

4. M. Ericsson and R. Sandstrom: 'Influence of welding speed on the fatigue of friction stir welds, and comparison with MIG and TIG', Int. J. Fatig., 2003, 25, (12), 1379-1387.

5. P. J. Withers: 'Residual stress and its role in failure', Rep. Prog. Phys., 2007, 70, 2211-2264.

6. K. Masubuchi: 'Analysis of welded structures: residual stresses, distortion, and their consequence', 600; 1980, Oxford, Pergamon.

7. Y. P. Yang, P. Dong, X. Tian and Z. Zhang: 'Prevention of hot cracking of high strength aluminum alloy by mechanical rolling', Proc. 5th Int. Conf. on 'Trends in welding research', Pine Mountain, GA, USA, June 1998, ASM, 700-705.

8. Y. P. Yang, P. Dong, J. Zhang and X. Tian: 'A hot cracking mitigation technique for TIG welding of high strength aluminum alloys', Weld. J. Res. Suppl., 2000, 79, 9s-17s.

9. S. W. Williams, D. A. Price, A. Wescott, C. J. C. Harrison, P. Staron and M. Kocak: 'Distortion control in welding by stress engineering', Proc. Conf. on Welding and brazing of aerospace structures - modern applications and materials for new and inservice parts', Berlin, Germany, May 2004, DVS Berichte, 95-101.

10. J. Altenkirch, A. Steuwer, P. J. Withers, S. W. Williams, M. Poad and S. W. Wen: 'Residual stress engineering in friction stir welds by roller tensioning', Sci. Technol. Weld., 2009, 14, 185-192.

11. P. Dong, J. K. Hong and P. Rogers: 'Analysis of residual stresses in Al-Li repair welds and mitigation techniques', Weld. J., 1998, 77, 439s-445s.

12. T. E. Barber, F. W. Brust, H. W. Mishler and M. F. Kanninen: 'Controlling residual stresses by heat sink welding', Report no. NP2159-LD, Electric Power Research Institute, Palo Alto, CA, USA, 1981.

13. Q. Guan, C. X. Zhang and D. L. Guo: 'Dynamic control of welding distortion by moving spot heat sink', Weld. World, 1994 , 33, 308-312.

14. J. Gabzdyl, M. Cole, S. W. Williams and D. Price: 'Control of laser weld distortion by thermal tensioning', in '20th ICALEO 2001', Vols. 92 and 93, 1236-1245; 2001, Orlando, FL, Laser Institute of America.

15. E. M. van der Aa, M. J. M. Hermans, I. M. Richardson, N. M. van der Pers and R. Delhez: 'Experimental study of the influence of a trailing heat sink on the welding residual stress distribution', Mater. Sci. Forum, 2006, 524-525, 479-484.

16. P. Staron, M. Kocak and S. Williams: 'Residual stresses in friction stir welded Al sheets', Appl. Phys. A, 2002, 74A, S1161-S1162.

17. D. G. Richards, P. B. Prangnell, S. W. Williams and P. J. Withers: 'Global mechanical tensioning for the management of residual stresses in welds', Mater. Sci. Eng., 2008, 489, 351-362.
18. G. Luan, G. Li, C. Li and C. Dong: 'DC-LSND friction stir welding', Proc. 7th Int. Symp. on 'Friction stir welding', Awaji Island, Japan, May 2008, TWI

19. R. V. Preston, S. D. Smith, H. R. Shercliff and P. J. Withers: 'Finite element modelling of tig welding aluminium alloy 2024', Sci. Technol. Weld. Join., 2003, 8, 10-18.

20. D. G. Richards, P. B. Prangnell, P. J. Withers, S. W. Williams, A Wescott and E. C. Oliver: 'FE modelling of mechanical tensioning for controlling residual stresses in friction stir welds', Mater. Sci. Forum, 2006, 539-543, 4025-4030.

21. J. Altenkirch, A. Steuwer, M. J. Peel, P. J. Withers, S. W. Williams and M. Poad: 'Mechanical tensioning of high-strength aluminum alloy friction stir welds', Metall. Mater. Trans. A, 2008, 39A, (13), 3246-3259.

22. R. V. Preston, H. R. Shercliff, P. J. Withers and S. Smith: 'Physically-based constitutive modelling of residual stress development in welding of Al alloy 2024', Acta Mater., 2004, 52, (17), 4973-4983.

23. Y. J. Chao and X. H. Qi: 'Thermal and thermo-mechanical modeling of friction stir welding of aluminum alloy 6061-T6', J. Mater. Process. Manuf. Sci., 1999, 7, (2), 215-233.

24. Y. J. Chao, X. H. Qi and W. Tang: 'Heat transfer in friction stir welding - experimental and numerical studies', Trans. ASME, 2003, 125, 138-145.

25. P. A. Colegrove, M. Painter, D. Graham and T. Miller: Proc. 2nd Int. Symp. on 'Friction stir welding', Gothenburg, Sweden, 1999, TWI.

26. P. A. Colegrove and H. R. Shercliff: 'Development of Trivex friction stir welding tool: Part I - two-dimensional flow modelling and experimental validation', Sci. Technol. Weld. Join., 2004, 9, (4), 345-351.

27. P. A. Colegrove and H. R. Shercliff: 'Development of the Trivex friction stir welding tool: Part II - three-dimensional flow modelling', Sci. Technol. Weld. Join., 2004, 9, 352-361.

28. P. A. Colegrove and H. R. Shercliff: '3-dimensional CFD modelling of flow round a threaded friction stir welding tool profile', J. Mater. Process. Technol., 2005, 169, (2), 320-327.

29. D. Price, C. Harrison, S. Williams, and A. Wescott: 'The performance of active tensioning techniques for stress control in welding', Report no. JS15232, BAE Systems, Bristol, UK, 2004

30. P. J. Withers, M. Preuss, A. Steuwer and J. W. L. Pang: 'Methods for the obtaining the strain-free lattice parameter when using diffraction to determine residual stress', J. Appl. Crystall., 2007, 40, 891-904.

31. M. T. Hutchings, P. J. Withers, T. M. Holden and T. Lorentzen 'Introduction to the characterisation of residual stresses by neutron diffraction', 424; 2005, London, CRC Press/Taylor \& Francis.

32. E. M. van der Aa: 'Local cooling during welding: prediction and control of residual stresses and buckling distortion', $\mathrm{PhD}$ thesis, Delft University of Technology, Delft, The Netherlands, 2006

33. J. Li: 'Localized thermal tensioning technique to prevent buckling distortion', Weld. World, 2005, 49, (11/12), 4-14.

34. P. Michaleris and X. Sun: 'Finite element analysis of thermal tensioning techniques mitigating weld buckling distortion', Weld. $J ., 1997,76,451 \mathrm{~s}-457 \mathrm{~s}$

35. R. M. Dull, J. R. Dydo and J. J. Russell: 'Transient thermal tensioning for control of buckling distortion', Proc. 82nd Ann. AWS Conv., Cleveland, OH, USA, May 2001, AWS, 95-96. 